\title{
Effector proteins of rust fungi
}

\author{
Benjamin Petre ${ }^{1,2,3}$, David L. Joly ${ }^{4}$ and Sébastien Duplessis ${ }^{1,2} *$ \\ 1 INRA, UMR 1136 Interactions Arbres/Microorganismes, Centre INRA Nancy Lorraine, Champenoux, France \\ ${ }^{2}$ UMR 1136 Interactions Arbres/Microorganismes, Faculté des Sciences et Technologies, Université de Lorraine, Vandoeuvre-lès-Nancy, France \\ ${ }^{3}$ The Sainsbury Laboratory, Norwich Research Park, Norwich, UK \\ ${ }^{4}$ Département de Biologie, Université de Moncton, Moncton, NB, Canada
}

\section{Edited by:}

Ken Shirasu, University of California,

Davis, USA

\section{Reviewed by:}

Ralf Thomas Voegele, Universität

Hohenheim, Germany

Jeffrey Ellis, Commonwealth

Scientific and Industrial Research

Organisation, Australia

\section{${ }^{*}$ Correspondence}

Sébastien Duplessis, INRA,

UMR 1136 Interactions

Arbres/Microorganismes,

Centre INRA Nancy Lorraine,

Champenoux 54280, France

e-mail:duplessi@nancy.inra.fr
Rust fungi include many species that are devastating crop pathogens. To develop resistant plants, a better understanding of rust virulence factors, or effector proteins, is needed. Thus far, only six rust effector proteins have been described: AvrP123, AvrP4, AvrL567, AvrM, RTP1, and PGTAUSPE-10-1. Although some are well established model proteins used to investigate mechanisms of immune receptor activation (avirulence activities) or entry into plant cells, how they work inside host tissues to promote fungal growth remains unknown. The genome sequences of four rust fungi (two Melampsoraceae and two Pucciniaceae) have been analyzed so far. Genome-wide analyses of these species, as well as transcriptomics performed on a broader range of rust fungi, revealed hundreds of small secreted proteins considered as rust candidate secreted effector proteins (CSEPs). The rust community now needs high-throughput approaches (effectoromics) to accelerate effector discovery/characterization and to better understand how they function in planta. However, this task is challenging due to the non-amenability of rust pathosystems (obligate biotrophs infecting crop plants) to traditional molecular genetic approaches mainly due to difficulties in culturing these species in vitro. The use of heterologous approaches should be promoted in the future.

Keywords: Pucciniales, rust fungi, genomics, transcriptomics, effectoromics

\section{THE KNOWN RUST FUNGAL EFFECTOR PROTEINS}

Plant pathogens secrete effector proteins into host tissues to promote infection through the manipulation of host processes (Win etal., 2012). During host colonization, rust fungi form haustoria that invaginate the host plasma membrane within the host cell cavity. These structures mediate the molecular traffic between the parasite and its host, and notably the delivery of effector proteins into host cells (Rafiqi et al., 2012), although other structures such as infection hyphae are also likely to be involved in this molecular traffic (Rafiqi etal., 2010). Until now, six effector proteins have been identified in three different rust species: AvrM, AvrL567, AvrP123, and AvrP4 in the flax rust fungus Melampsora lini, the Rust Transferred Protein RTP1 in the bean rust fungus Uromyces fabae, and PGTAUSPE10-1 in the wheat stem rust fungus Puccinia graminis f. sp. tritici (Table 1; Kemen et al., 2005; Ellis et al., 2007; Upadhyaya et al., 2014). They are all secreted proteins expressed in haustoria, with no clearly identified biochemical function. How they promote fungal growth inside host tissues remains unknown (Table 1). In contrast, their avirulence (Avr) properties (i.e., the ability to trigger specific immune responses) and/or their trafficking mechanisms (i.e., how they enter plant cells) are better understood.

The four M. lini effector proteins were first identified as effectors due to their Avr properties (Ellis et al., 2007). More recently, a screen with a bacterial protein delivery system in wheat revealed the $P$. graminis $\mathrm{f}$. sp. tritici protein PGTAUSPE-10-1 which causes cell death in the host line carrying the resistance gene Sr22; PGTAUSPE-10-1 was thus considered as a candidate AvrRs22 effector (Upadhyaya et al., 2014). M. lini AvrL567 and AvrM are model Avrs for the study of effector recognition by immune receptors. Both proteins are recognized inside plant cells by specific immune receptors following a direct physical interaction (Table 1; Dodds et al., 2004, 2006; Catanzariti et al., 2006, 2010). For both effectors, 3D structure-driven amino acid substitutions revealed multiple contact points mediating the interaction with their cognate receptor (Wang et al., 2007; Ravensdale et al., 2011; Ve et al., 2013). Amino acid residues within these contact points are highly variable, suggesting that an arms race is taking place between these effectors and their corresponding receptors. Such knowledge of Avr-receptor interactions is valuable for engineering improved immune receptors with expanded effector recognition (Harris et al., 2013; Segretin et al., 2014), which may ultimately help to develop broad-spectrum resistance in plants (Dangl et al., 2013).

All six rust effector proteins are thought to be translocated from haustoria into host cells (Table 1). RTP1 and AvrM have been directly shown to traffic from haustoria to plant cells during infection (Kemen et al., 2005, 2013; Rafiqi et al., 2010), whereas the direct recognition of AvrM and AvrL567 by cytosolic plant immune receptors indirectly demonstrates their internalization in the plant cell (Ellis et al., 2007). Current mechanistic models based on pathogen-free assays suggest that AvrP4, AvrM, and AvrL567 proteins can enter plant cells autonomously (Catanzariti etal., 2006; Kale et al., 2010; Rafiqi et al., 2010). Rafiqi et al. (2010) further showed that AvrL567 and AvrM cell entry is mediated by divergent $\mathrm{N}$-terminal uptake domains, carrying hydrophobic residues that are critical for cell entry in the case of 
Table 1 | Rust effector proteins.

\begin{tabular}{|c|c|c|c|c|c|c|c|}
\hline $\begin{array}{l}\text { Effector } \\
\text { protein }\end{array}$ & $\begin{array}{l}\text { aa residues } \\
\text { (mature) }\end{array}$ & $\begin{array}{l}\text { Signal } \\
\text { peptide }\end{array}$ & Expression & $\begin{array}{l}\text { Localization in } \\
\text { infected tissues }\end{array}$ & $\begin{array}{l}\text { Avr property } \\
\text { (immune receptor) }\end{array}$ & $\begin{array}{l}\text { Biochemical } \\
\text { function }\end{array}$ & $\begin{array}{l}\text { Role in } \\
\text { virulence }\end{array}$ \\
\hline AvrM & $284-347$ & Yes & Haustorium $^{a}$ & $\begin{array}{l}\text { Haustorium, } \\
\text { EHMx, plant } \\
\text { cytosol }^{a}\end{array}$ & Yes (M) & nd & nd \\
\hline AvrL567 & 127 & Yes & Haustorium & Plant cytosol & Yes (L5, L6, L7) & nd & nd \\
\hline AvrP4 & 65 & Yes & Haustorium & Plant cytosol & Yes (P4) & nd & nd \\
\hline RTP1 & 201 & Yes & Haustoriuma $^{a}$ & $\begin{array}{l}\text { Haustorium/ } \\
\text { EHMx/plant } \\
\text { cytosol/ plant } \\
\text { nucleus }^{\text {a }}\end{array}$ & nd & $\begin{array}{l}\text { Protease } \\
\text { inhibitor/filament- } \\
\text { forming }\end{array}$ & nd \\
\hline
\end{tabular}

The table details the rust fungi effector proteins reported so far.

Avr, Avirulence; aa, amino acid; EHMx, extra-haustorial matrix; nd, not determined; ND, not detected; np, not published.

a Direct evidence of the presence of the protein acquired by immunolocalization.

$\mathrm{b}$ a host-specific toxic effect was detected.

AvrM (Ve et al., 2013). This model and the assays used to build it are currently debated, and the need to study effector trafficking during the infection has been stressed (Petre and Kamoun, 2014).

Effector proteins are anticipated to be key molecules for pathogenicity, although very little is known about how they function within host tissues. Among the six characterized rust effectors, none possess a clearly identified biochemical function or a detected virulence activity (Table 1). Indeed, M. lini transgenic lines silencing AvrL567 did not show any reduced growth on flax, suggesting that this effector is not required for full virulence (Lawrence et al., 2010). As discussed by the authors, this could be explained by a high functional redundancy in the $M$. lini effector repertoire (Lawrence et al., 2010). Such redundancy was also observed in the effector repertoires of bacterial plant pathogens (Kvitko et al., 2009), and represents an obstacle for the functional characterization of virulence effector functions through genetic approaches. However, recent progresses have been made regarding RTP1, a conserved rust effector that seems to work as a protease inhibitor (Pretsch et al., 2013). On the other hand, Kemen et al. (2013) reported that RTP1 accumulates within the host-parasite interface and forms filaments. The authors proposed a role as a structural effector, possibly stabilizing fungal structures during infection. A model that integrates the different RTP1 localizations and proposed functions remains to be drawn. Several methods for the genetic transformation of $M$. lini and U. fabae, as well as for host-induced gene silencing (HIGS) of Puccinia triticina have been reported (Lawrence etal., 2010; Djulic etal., 2011; Panwar etal., 2013). Such methods, although they are still at various stages of development, represent valuable tools to investigate the contribution of individual effectors to virulence during infection.

\section{POST-GENOMIC APPROACHES IDENTIFY A PLETHORA OF RUST SECRETED PROTEINS CONSIDERED AS CANDIDATE EFFECTORS}

In the past few years, a typical profile has emerged for plant pathogen effectors. Fungal proteins are usually considered candidate secreted effector proteins (CSEPs) if they possess a signal peptide for secretion, a small size and no other targeting sequence or transmembrane domains (Stergiopoulos and de Wit, 2009; Rouxel and Tyler, 2012; Saunders et al., 2012). Such CSEPs attract more attention when they are expressed during infection or when they present signatures of rapid evolution. Besides, expression in specific infection structures such as haustoria, often considered as a major site of effector delivery, provides another level of information. Some authors also take advantage of conserved amino acid motifs or predicted protein structures to establish large CSEP classes (Godfrey et al., 2010; Pedersen etal., 2012). Homology to known rust effectors and organization in gene families or in physical clusters have also been considered to refine these sets of CSEPs (Hacquard et al., 2012; Saunders et al., 2012). In rust fungi, such criteria have been applied in the frame of effector mining pipelines that combined genome-wide analyses and transcriptomics to reveal amazingly rich catalogs of rust CSEPs (Cantu et al., 2011, 2013; Duplessis et al., 2011a; Fernandez et al., 2012; Hacquard et al., 2012; Saunders etal., 2012; Garnica et al., 2013; Zheng et al., 2013; Bruce etal., 2014; Link etal., 2014; Nemri etal., 2014; Table 2).

\section{GENOME-WIDE ANALYSES OF CSEPS}

The genome sequences of four rust species have been published so far: Melampsora larici-populina (poplar leaf rust fungus; Duplessis et al., 2011a), M. lini (flax rust fungus; Nemri et al., 2014), P. graminis f. sp. tritici (wheat stem rust fungus; 


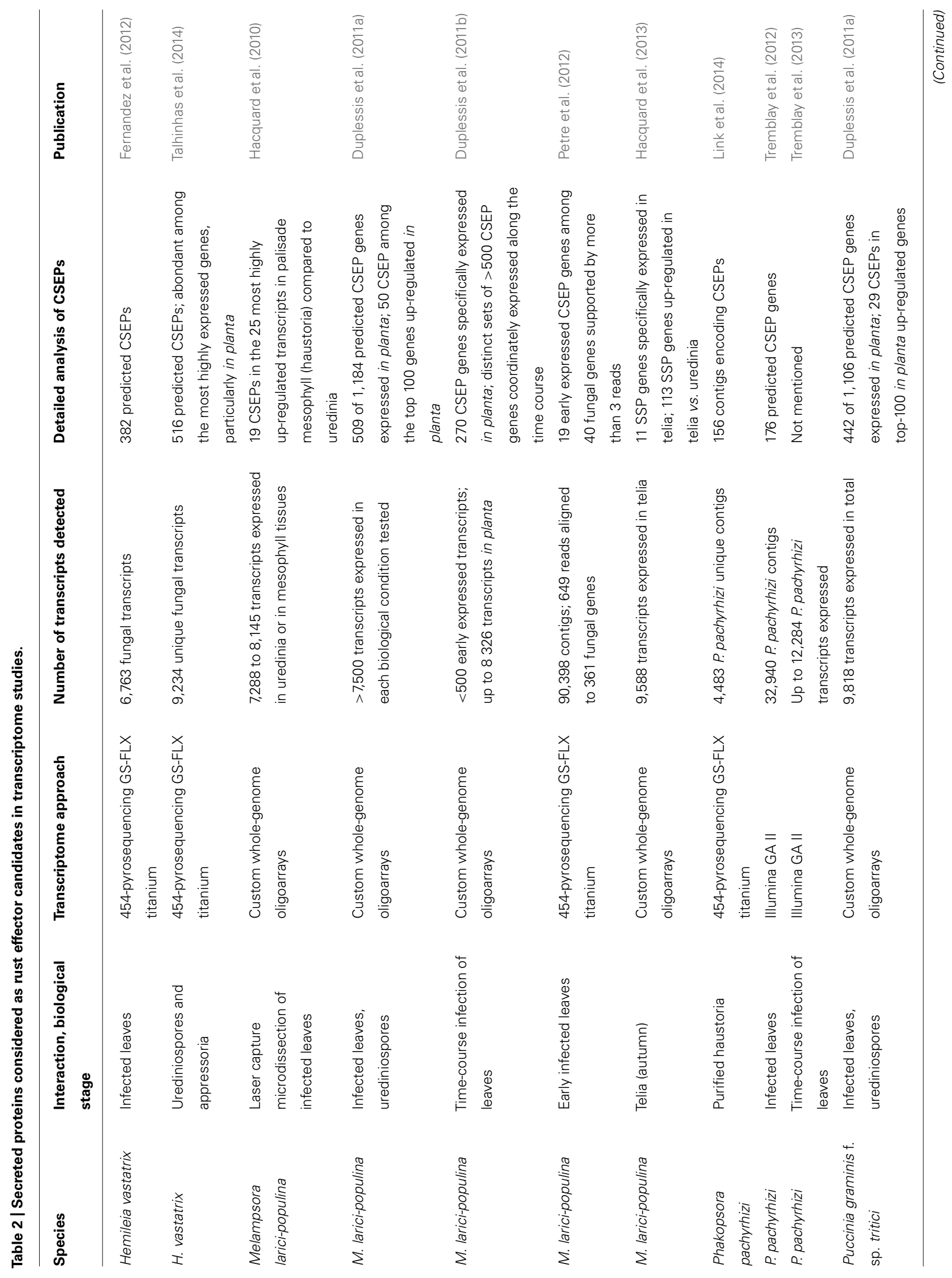


Duplessis et al., 2011a) and Puccinia striiformis f. sp. tritici (wheat stripe rust fungus; Cantu et al., 2011, 2013; Zheng et al., 2013). Genome-wide effector mining in these four species revealed hundreds of genes encoding CSEPs. In M. larici-populina, 1,184 CSEPs have been identified from 1,898 genes encoding predicted secreted proteins (Duplessis et al., 2011a). In M. lini, 762 priority CSEPs were selected from 1,085 genes encoding predicted secreted proteins (Nemri et al., 2014). In P. graminis f. sp. tritici, 1,106 CSEP genes were selected from 1,934 genes encoding predicted secreted proteins (Duplessis et al., 2011a). In P. striiformis f. sp. tritici, different reports of selected sets of CSEPs have been published. In this rust fungus, a total of 2,092 CSEP coding genes were considered in isolate CY-32 (Zheng et al., 2013) while the draft genome of isolate PST-130 led to 1,088 filtered CSEPs out of 1,188 genes coding predicted secreted protein (Cantu et al., 2011). However, genome re-sequencing of four other isolates and cross-comparison with PST-130 has led to a revision of gene numbers and to a larger set of 2,999 predicted CSEPs (Cantu et al., 2013).

All rust fungi genomes are marked by expansions of gene families, particularly those encoding secreted proteins. For instance, the largest CSEP gene family in M. larici-populina includes 111 members (Duplessis et al., 2011a). Noteworthy, a part of these genes were not predicted by algorithms but rather found by manual curation, highlighting the importance of expert annotation of these atypical gene families of small proteins (Duplessis et al., 2011a; Hacquard et al., 2012). This last observation is important to consider when performing cross-comparison between genomes showing different degrees of annotation. Since RXLR or LXLFLAK conserved motifs found in oomycetes helped defining large effector families (Win et al., 2007), a particular focus on motif search was given in rust CSEPs. The motif [YFW] $\mathrm{xC}$ has been reported in the genomes of obligate biotrophic pathogens of cereals, including P. graminis f. sp. tritici (Godfrey et al., 2010). In M. larici-populina, this motif is common, eventually with positional constraints, but with no restriction to the N-terminus of CSEPs (Hacquard et al., 2012). Nonetheless, functional and structural characterization for the [YFW] $\mathrm{xC}$ motif is lacking at the moment, and no evidence for a role in translocation has been provided so far.

Another common trend observed in rust candidate effector repertoires is the large proportion of species-, family- or order-specific CSEPs (Duplessis et al., 2014a). A large majority of species-specific CSEP genes (nearly 70\%) were first observed in $M$. larici-populina. With the sequencing of the flax rust genome this number has reduced, as only $4 \%$ of the M. lini CSEP genes were found to be species-specific and more than half had a homolog in one of the three other sequenced rust genomes (Nemri et al., 2014). Interestingly, M. lini Avr genes homologs are only found in M. larici-populina and thus could be considered family-specific effectors, whereas other genes such as Uromyces spp. RTP1 or some Haustorially Expressed Secreted Proteins (HESPs) identified in M. lini are conserved across rust fungi (Fernandez et al., 2012). Sequencing more genomes among Pucciniales, particularly in uncovered taxonomic families, will definitely help defining the common set of core rust effectors and those that may be related to host adaptation (Duplessis et al., 2014b). 


\section{TRANSCRIPTOMICS IDENTIFY CSEPS IN MANY RUST SPECIES}

Rust fungi have rather large genomes (89-190 Mb) and an important content in repetitive elements ( $>43 \%$ of total genomes), which impedes the systematic sequencing and assembly of targeted species (Duplessis et al., 2014b). Indeed, genome size estimates for certain rust species go beyond the numbers given above (Leonard and Szabo, 2005; Tavares et al., 2014). Whole-genome oligoarrays or RNA-Seq has thus proven to be useful in gathering relevant information about the transcriptomes of rust fungi. A strong stage specific regulation of protein secretion has been demonstrated in U. fabae (Link and Voegele, 2008), and novel high-throughput approaches confirmed a coordinated expression of CSEPs during host infection, in a temporal (expression at specific time-points) or spatial (expression in specific structures) manner (Table 2). For instance, transcripts profiling during timecourse infection of poplar leaves by M. larici-populina revealed waves of expression for more than 500 CSEP transcripts (Hacquard etal., 2010; Duplessis etal., 2011b; Petre etal., 2012). Moreover, such temporal succession of expression patterns has been confirmed in other rust species such as Hemileia vastatrix (Fernandez et al., 2012), P. striiformis f. sp. tritici (Cantu etal., 2013), and Puccinia triticina (Bruce et al., 2014). This highlights the need for a better understanding of expression regulation in rust fungi, whether by transcription factors or via epigenetic control, such as reported in Phytophthora infestans or in Leptosphaeria maculans (Judelson, 2012; Soyer et al., 2014).

Interestingly, different reports showed that $U$. fabae RTP1 homologs may have different localizations (Kemen et al., 2005; Hacquard et al., 2012). RTP1 also exhibits a dynamic pattern of localization in the extra-haustorial matrix and within host cells during the infection process (Kemen et al., 2013), illustrating once more that rust effectors deployment is probably finely regulated in time and space. In this regard, a major issue with in planta expression study is the occurrence of different fungal cell types (germ tubes, appressoria, substomatal vesicles, infection hyphae, haustoria, sporogenous hyphae, and newly formed spores), which implies that the observed expression levels are often a mixture of different cell types at different stages. After the seminal paper that described a method to purify haustoria from the bean rust fungus (Hahn and Mendgen, 1997) and the one reporting on M. lini HESPs that included several Avr genes (Catanzariti et al., 2006), haustoria purification has been combined with RNA-Seq studies to prioritize CSEPs likely delivered by these infection structures (Cantu et al., 2013; Garnica et al., 2013, Link et al., 2014). Laser capture microdissection has also been coupled to transcriptomics to distinguish between biotrophic and sporogenous areas in poplar leaves infected by M. larici-populina (Hacquard et al., 2010). This study demonstrated that CSEPs are predominantly and highly expressed in the area containing infection hyphae and haustoria.

In order to complete their life cycle, heterecious rust fungi infect two unrelated host species. To do so, it is likely that they express host-specific effector sets. However, except for the wheat leaf rust $P$. triticina (Xu etal., 2011), only a small portion of the life cycle has been surveyed in most rust species. Recently, in order to expand our understanding of the transcriptome of M. larici-populina, gene expression analyses were conducted on rust telia collected from decaying leaves (Hacquard et al., 2013). This study revealed that CSEP-encoding genes were expressed in these tissues, suggesting that CSEPs might have additional roles unrelated to the interaction with the living host plant (Hacquard et al., 2013). Ongoing transcriptome profiling studies in different rust species will help to determine the sets of CSEP genes expressed along the life cycle. Such studies may reveal CSEPs with a host-specific expression, which represent host-adapted effectors (Duplessis et al., 2014b).

\section{TOWARDS UNIFIED EFFECTOR MINING AND EFFECTOROMICS PIPELINES}

Various studies combined genome sequencing and transcriptomics to provide sets of CSEPs. Automated pipelines for effector mining should be unified and systematically applied to forthcoming rust fungi genomes to provide a solid foundation for future comparative analyses in Pucciniales. However, an important point to consider is the need for an accurate curation of CSEP-encoding genes in these genomes and the screening of additional time points in time-course studies and/or spore stages. Some early genomewide surveys of CSEPs in plant interacting fungi arbitrarily focused on small proteins because of the commonly observed small size of effectors and in order to reduce manual gene curation efforts (Stergiopoulos and de Wit, 2009, Duplessis et al., 2011a). Considering that rust fungi effectors can exhibit greater size (e.g., $M$. lini AvrM), such an arbitrary cut-off should not be considered in future analyses of rust CSEPs.

To face the growing number of CSEPs made available by effector mining studies, and to better understand their functions in plant cells, we need tools to study them directly in planta. This relies on the ability to genetically transform the plant to perform high-throughput functional analyses (also referred to as "effectoromics"). Rust fungi hosts (e.g., wheat, soybean, flax, or poplar), are not easily amenable to molecular genetic approaches. However, non-host model plants can be used to characterize and screen CSEPs. For instance, the Agrobacterium-mediated transient genetic transformation of Nicotiana benthamiana has proven useful to rapidly express effector proteins into plant cell, but has been largely ignored in rust effector biology. This system allows combining many different approaches (cell-biology, protein biochemistry, hypersensitive response and infection assays) all in one. Thus, such approaches may help in (1) determining the sub-cellular localization of candidate effector proteins using effector-fluorescent protein fusions, (2) identifying interacting partners within protein complexes, (3) detecting candidate effector capacity to enhance susceptibility during infection with selected N. benthamiana pathogens (thus validating a role in virulence), and (4) testing their recognition by specific immune receptors.

\section{AUTHOR CONTRIBUTIONS}

Benjamin Petre and Sébastien Duplessis compiled data from the literature and drafted the manuscript. All the authors wrote and revised the article.

\section{ACKNOWLEDGMENTS}

The authors would like to thank the reviewers for their helpful comments to set the final version of this article. Benjamin Petre 
thanks Diane Saunders (JIC, UK), Sophien Kamoun (TSL, UK), and Kofyorty Stactafyzal (NRP, UK) for great discussions. Benjamin Petre is supported by INRA, in the framework of a Contrat Jeune Scientifique, by the European Union, in the framework of the Marie-Curie FP7 COFUND People Programme, through the award of an AgreenSkills' fellowship (under grant agreement no. 267196) and by the LABEX Arbre, through the award of a mobility grant. Research in The Sainsbury Lab is supported by the Gatsby Charitable Foundation, the European Research Council, and the Biotechnology and Biological Sciences Research Council (BBSRC). Research in David L. Joly lab is supported by the New Brunswick Innovation Foundation. Sébastien Duplessis acknowledges the support of the French ANR for a grant part of the "Investissements d'Avenir" program (ANR-11-LABX0002-01, Lab of Excellence ARBRE) and the Young Scientist Grant POPRUST to Sébastien Duplessis (ANR-2010-JCJC-1709-01), and the Région Lorraine.

\section{REFERENCES}

Bruce, M., Neugebauer, K. A., Joly, D. L., Migeon, P., Cuomo, C. A., Wang, S., et al. (2014). Using transcription of six Puccinia triticina races to identify the effective secretome during infection of wheat. Front. Plant Sci. 4:520 doi: 10.3389/fpls.2013.00520

Cantu, D., Govindarajulu, M., Kozik, A., Wang, M., Chen, X., Kojima, K. K., et al. (2011). Next generation sequencing provides rapid access to the genome of Puccinia striiformis $\mathrm{f}$. sp. tritici, the causal agent of wheat stripe rust. PLoS ONE 6:e24230. doi: 10.1371/journal.pone.0024230

Cantu, D., Segovia, V., MacLean, D., Bayles, R., Chen, X., Kamoun, S., et al. (2013). Genome analyses of the wheat yellow (stripe) rust pathogen Puccinia striiformis f. sp. tritici reveal polymorphic and haustorial expressed secreted proteins as candidate effectors. BMC Genomics 14:270. doi: 10.1186/1471-2164$14-270$

Catanzariti, A-M., Dodds, P. N., Lawrence, G. J., Ayliffe, M. A., and Ellis, J. G. (2006). Haustorially expressed secreted proteins from flax rust are highly enriched for avirulence elicitors. Plant Cell 18, 243-256. doi: 10.1105/tpc.105.035980

Catanzariti, A-M., Dodds, P. N., Ve, T., Kobe, B., Ellis, J. G., and Staskawicz, B. J. (2010). The AvrM effector from flax rust has a structured C-terminal domain and interacts directly with the $\mathrm{M}$ resistance protein. Mol. Plant Microbe Interact. 23, 49-57. doi: 10.1094/MPMI-23-1-0049

Dangl, J. L., Horvath, D. M., and Staskawicz, B. J. (2013). Pivoting the plant immune system from dissection to deployment. Science 341, 746-751. doi: $10.1126 /$ science. 1236011

Djulic, A., Schmid, A., Lenz, H., Sharma, P., Koch, C., Wirsel, S. G., et al. (2011). Transient transformation of the obligate biotrophic rust fungus Uromyces fabae using biolistics. Fungal Biol. 115, 633-642. doi: 10.1016/j.funbio.2011.03.007

Dodds, P. N., Lawrence, G. J., Catanzariti, A. M., Ayliffe, M. A., and Ellis, J. G. (2004). The Melampsora lini AvrL567 avirulence genes are expressed in haustoria and their products are recognized inside plant cells. Plant Cell 16, 755-768. doi: 10.1105/tpc.020040

Dodds, P. N., Lawrence, G. J., Catanzariti, A. M., Teh, T., Wang, C. I., Ayliffe, MA., et al. (2006). Direct protein interaction underlies gene-for-gene specificity and coevolution of the flax resistance genes and flax rust avirulence genes. Proc. Natl. Acad. Sci. U.S.A. 103, 8888-8893. doi: 10.1073/pnas.0602577103

Duplessis, S., Cuomo, C. A., Lin, Y.-C., Aerts, A., Tisserant, E., VeneaultFourrey, C., et al. (2011a). Obligate biotrophy features unraveled by the genomic analysis of rust fungi. Proc. Natl. Acad. Sci. U.S.A. 108, 9166-9171. doi: 10.1073/pnas.1019315108

Duplessis, S., Hacquard, S., Delaruelle, C., Tisserant, E., Frey, P., Martin, F., et al. (2011b). Melampsora larici-populina transcript profiling during germination and time-course infection of poplar leaves reveals dynamic expression patterns associated with virulence and biotrophy. Mol. Plant Microbe Interact. 24, 808-818. doi: 10.1094/MPMI-01-11-0006

Duplessis, S., Joly, D. J., and Dodds, P. N. (2012). "Rust effectors," in Effectors in PlantMicrobes Interactions, eds F. Martin and S. Kamoun (Oxford: Wiley-Blackwell), 155-193.
Duplessis, S., Spanu, P. D., and Schirawski, J. (2014a). "Biotrophic fungi (powdery mildews, Rusts and Smuts)," in Ecological Genomics of the Fungi. Plant-Interacting Fungi Section, ed F. Martin (Hoboken, NJ: Wiley-Blackwell), 149-168.

Duplessis, S., Bakkeren, G., and Hamelin, R. (2014b). Advancing knowledge on biology of rust fungi through genomics. Adv Bot. Res. 70, 173-209. doi: 10.1016/B978-0-12-397940-7.00006-9

Ellis, J. G., Dodds, P. N., and Lawrence, G. J. (2007). Flax rust resistance gene specificity is based on direct resistance-avirulence protein interactions. Annu. Rev. Phytopathol. 45, 289-306. doi: 10.1146/annurev.phyto.45.062806. 094331

Fernandez, D., Tisserant, E., Talhinhas, P., Azinheira, H., Vieira, A., Petitot, A-S., et al. (2012). 454-pyrosequencing of Coffea arabica leaves infected by the rust fungus Hemileia vastatrix reveals in planta-expressed pathogen-secreted proteins and plant functions in a late compatible plant-rust interaction. Mol. Plant Pathol. 13, 17-37. doi: 10.1111/j.1364-3703.2011.00723.x

Garnica, D. P., Upadhyaya, N. M., Dodds, P. N., and Rathjen, J. P. (2013). Strategies for wheat stripe rust pathogenicity identified by transcriptome sequencing. PLoS ONE 8:e67150. doi: 10.1371/journal.pone.0067150

Godfrey, D., Böhlenius, H., Pedersen, C., Zhang, Z., Emmersen, J., and ThordalChristensen, H. (2010). Powdery mildew fungal effector candidates share N-terminal Y/F/WxC-motif. BMC Genomics 11:317. doi: 10.1186/1471-216411-317

Hacquard, S., Delaruelle, C., Legué, V., Tisserant, E., Kohler, A., Frey, P., et al. (2010). Laser capture microdissection of uredinia formed by Melampsora larici-populina revealed a transcriptional switch between biotrophy and sporulation. Mol. Plant Microbe Interact. 23, 1275-1286. doi: 10.1094/MPMI-05-10-0111

Hacquard, S., Delaruelle, C., Frey, P., Tisserant, E., Kohler, A., and Duplessis, S. (2013). Transcriptome analysis of poplar rust telia reveals overwintering adaptation and tightly coordinated karyogamy and meiosis processes. Front. Plant Sci. 4:456. doi: 10.3389/fpls.2013.00456

Hacquard, S., Joly, D. L., Lin, Y.-C., Tisserant, E., Feau, N., Delaruelle, C., et al. (2012). A comprehensive analysis of genes encoding small secreted proteins identifies candidate effectors in Melampsora larici-populina (poplar leaf rust). Mol. Plant Microbe Interact. 25, 279-293. doi: 10.1094/MPMI-09-11-0238

Hahn, M., and Mendgen, K. (1997). Characterization of in planta-induced rust genes isolated from a haustorium-specific cDNA library. Mol. Plant Microbe Interact. 10, 427-437. doi: 10.1094/MPMI.1997.10.4.427

Harris, C. J., Slootweg, E. J., Goverse, A., and Baulcombe, D. C. (2013). Stepwise artificial evolution of a plant disease resistance gene. Proc. Natl. Acad. Sci. U.S.A. 110, 21189-21194. doi: 10.1073/pnas.1311134110

Judelson, H. (2012). Dynamics and innovations within oomycete genomes: insights into biology, pathology, and evolution. Eukaryot. Cell 11, 1304-1312. doi: 10.1128/ec.00155-12

Kale, S. D., Gu, B., Capelluto, D. G., Dou, D., Feldman, E., Rumore, A., et al. (2010). External lipid PI3P mediates entry of eukaryotic pathogen effectors into plant and animal host cells. Cell 142, 284-295. doi: 10.1016/j.cell.2010. 06.008

Kemen, E., Kemen, A., Ehlers, A., Voegele, R., and Mendgen, K. (2013). A novel structural effector from rust fungi is capable of fibril formation. Plant J. 75, 767-780. doi: 10.1111/tpj.12237

Kemen, E., Kemen, A. C., Rafiqi, M., Hempel, U., Mendgen, K., Hahn, M., et al. (2005). Identification of a protein from rust fungi transferred from haustoria into infected plant cells. Mol. Plant Microbe Interact. 18, 1130-1139. doi: 10.1094/MPMI-18-1130

Kvitko, B. H., Park, D. H., Velasquez, A. C., Wei, C-F., Russel, A. B., Martin, G. B., et al. (2009). Deletions in the repertoire of Pseudomonas syringae pv. tomato DC3000 type III secretion effector genes reveal functional overlap among effectors. PLoS Pathog. 5:e1000388. doi: 10.1371/journal.ppat.1000388

Lawrence, G. J., Dodds, P. N., and Ellis, J. G. (2010). Transformation of the flax rust fungus, Melampsora lini: selection via silencing of an avirulence gene. Plant J. 61, 364-369. doi: 10.1111/j.1365-313X.2009.04052.x

Leonard, K. J., and Szabo, L. J. (2005). Stem rust of small grains and grasses caused by Puccinia graminis. Mol. Plant Pathol. 6, 99-111. doi: 10.1111/j.13643703.2005.00273.x

Link, T. I., Lang, P., Scheffler, B. E., Duke, M. V., Graham, M. A., Cooper, B., et al. (2014). The haustorial transcriptomes of Uromyces appendiculatus and Phakopsora pachyrhizi and their candidate effector families. Mol. Plant Pathol. 15, 379-393. doi: 10.1111/mpp.12099 
Link, T. I., and Voegele, R. T. (2008). Secreted proteins of Uromyces fabae: similarities and stage specificity. Mol. Plant Pathol. 9, 59-66. doi: 10.1111/j.13643703.2007.00448.x

Nemri, A., Saunders, D. G., Anderson, C., Upadhyaya, N. M., Win, J., Lawrence, G. J., et al. (2014). The genome sequence and effector complement of the flax rust pathogen Melampsora lini. Front. Plant Sci. 5:98. doi: 10.3389/fpls.2014. 00098

Panwar, V., McCallum, B., and Bakkeren, G. (2013). Endogenous silencing of Puccinia triticina pathogenicity genes through in planta-expressed sequences leads to the suppression of rust diseases on wheat. Plant J. 73, 521-532. doi: 10.1111/tpj.12047

Pedersen, C., Ver Loren van Themaat, E., McGuffin, L. J., Abbott, J. C., Burgis, T. A., Barton, G., et al. (2012). Structure and evolution of barley powdery mildew effector candidates. BMC Genomics 13:694. doi: 10.1186/1471-216413-694

Petre, B., and Kamoun, S. (2014). How do filamentous pathogens deliver effector proteins into plant cells? PLoS Biol. 12:e1001801. doi: 10.1371/journal.pbio.1001801

Petre, B., Morin, E., Tisserant, E., Hacquard, S., Da Silva, C., Poulain, J., et al. (2012) RNA-Seq of early-infected poplar leaves by the rust pathogen Melampsora laricipopulina uncovers PtSultr3;5, a fungal-induced host sulfate transporter. PLoS ONE 7:e44408. doi: 10.1371/journal.pone.0044408

Pretsch, K., Kemen, A., Kemen, E., Geiger, M., Mendgen, K., and Voegele, R. (2013). The rust transferred proteins-a new family of effector proteins exhibiting protease inhibitor function. Mol. Plant Pathol. 14, 96-107. doi: 10.1111/j.13643703.2012.00832.x

Rafiqi, M., Gan, P. H., Ravensdale, M., Lawrence, G. J., Ellis, J. G., Jones, D. A., et al. (2010). Internalization of flax rust avirulence proteins into flax and tobacco cells can occur in the absence of the pathogen. Plant Cell 22, 2017-2032. doi: $10.1105 /$ tpc. 109.072983

Rafiqi, M., Ellis, J. G., Ludowici, V. A., Hardham, A. R., and Dodds, P. N. (2012). Challenges and progress towards understanding the role of effectors in plantfungal interactions. Curr. Opin. Plant Biol 15, 477-82. doi: 10.1016/j.pbi.2012. 05.003

Ravensdale, M., Bernoux, M., Ve, T., Kobe, B., Thrall, P. H., Ellis, J. G., et al. (2011). Intramolecular interaction influences binding of the Flax L5 and L6 resistance proteins to their AvrL567 ligands. PLoS Pathog. 8:e1003004. doi: 10.1371/journal.ppat.1003004

Rouxel, T., and Tyler, B. M. (2012). "Effector of fungi and Oomycetes: their virulence and avirulence functions and translocation from pathogen to host cells," in Molecular Plant Immunity, ed. G. Sessa (Oxford: John Wiley \& Sons), 123-167.

Saunders, D. G., Win, J., Cano, L. M., Szabo, L. J., Kamoun, S., and Raffaele, S. (2012). Using hierarchical clustering of secreted protein families to classify and rank candidate effectors of rust fungi. PLOS ONE 7:e29847. doi: 10.1371/journal.pone.0029847

Segretin, M. E., Pais, M., Franceschetti, M., Chaparro-Garcia, A., Bos, J. I., Banfield, M. J., et al. (2014). Single amino acid mutations in the potato immune receptor R3a expand response to Phytophthora effectors. Mol. Plant Microbe Interact. 27, 624-637. doi: 10.1094/MPMI-02-14-0040-R

Soyer, J. L., El Ghalid, M., Glaser, N., Ollivier, B., Linglin, J., Grandaubert, J., etal. (2014). Epigenetic control of effector gene expression in the plant pathogenic fungus Leptosphaeria maculans. PLoS Genetics 10:e1004227. doi: 10.1371/journal.pgen.1004227

Stergiopoulos, I., and de Wit, P. J. (2009). Fungal effector proteins. Annu. Rev. Phytopathol. 47, 233-263. doi: 10.1146/annurev.phyto.112408.132637

Talhinhas, P., Azinheira, H. G., Vieira, B., Loureiro, A., Tavares, S., Batista, D., et al. (2014). Overview of the functional virulent genome of the coffee leaf rust pathogen Hemileia vastatrix with an emphasis on early stages of infection. Front. Plant Sci. 5:88. doi: 10.3389/fpls.2014.00088

Tavares, S., Ramos, A. P., Pires, A. S., Azinheira, H. G., Caldeirinha, P., Link, T., et al. (2014). Genome size analyses of Pucciniales reveal the largest fungal genomes. Front. Plant Sci. 5:422. doi: 10.3389/fpls.2014.00422

Tremblay, A., Hosseini, P., Li, S., Alkharouf, N. W., and Matthews, B. F. (2012). Identification of genes expressed by Phakopsora pachyrhizi, the pathogen causing soybean rust, at a late stage of infection of susceptible soybean leaves. Plant Pathol. 61, 773-786. doi: 10.1111/j.1365-3059.2011. 02550.x

Tremblay, A., Hosseini, P., Li, S., Alkharouf, N. W., and Matthews, B. F. (2013). Analysis of Phakopsora pachyrhizi transcript abundance in critical pathways at four time-points during infection of a susceptible soybean cultivar using deep sequencing. BMC Genomics 11:614. doi: 10.1186/1471-2164-14-614

Upadhyaya, N. M., Mago, R., Staskawicz, B. J., Ayliffe, M. A., Ellis, J. G., and Dodds, P. N. (2014). A bacterial type III secretion assay for delivery of fungal effector proteins into wheat. Mol. Plant Microbe Interact. 27, 255-264. doi: 10.1094/MPMI-07-13-0187-FI

Ve, T., Williams, S. J., Catanzariti, A-M., Rafiqi, M., Rahman, M., Ellis, J. G., et al. (2013). Structures of the flax-rust effector AvrM reveal insights into the molecular basis of plant-cell entry and effector-triggered immunity. Proc. Natl. Acad. Sci. U.S.A. 110, 17594-17599. doi: 10.1073/pnas.1307614110

Wang, C. I., Guncar, G., Forwood, J. K., Teh, T., Catanzariti, A. M., Lawrence, G. J., et al. (2007). Crystal structures of flax rust avirulence proteins AvrL567-A and -D reveal details of the structural basis for flax disease resistance specificity. Plant Cell 19, 2898-2912. doi: 10.1105/tpc.107.053611

Win, J., Chaparro-Garcia, A., Belhaj, K., Saunders, D. G., Yoshida, K., Dong, S., et al. (2012). Effector biology of plant-associated organisms: concepts and perspectives. Cold. Spring Harb. Symp. Quant. Biol. 77, 235-247 doi: 10.1101/sqb.2012. 77.015933

Win, J., Morgan, W., Bos, J., Krasileva, K. V., Cano, L. M., Chaparro-Garcia, A., et al. (2007). Adaptive evolution has targeted the C-terminal domain of the RXLR effectors of plant pathogenic oomycetes. Plant Cell 19, 2349-2369. doi: $10.1105 /$ tpc.107.051037

Xu, J., Linning, R., Fellers, J., Dickinson, M., Zhu, W., Antonov, I., et al. (2011). Gene discovery in EST sequences from the wheat leaf rust fungus Puccinia triticina sexual spores, asexual spores and haustoria, compared to other rust and corn smut fungi. BMC Genomics 12:161. doi: 10.1186/1471-2164-12-161

Zheng, W., Huang, L., Huang, J., Wang, X., Chen, X., Zhao, J., et al. (2013). High genome heterozygosity and endemic genetic recombination in the wheat stripe rust fungus. Nat. Commun. 4, 2673 doi: 10.1038/ncomms3673

Conflict of Interest Statement: The authors declare that the research was conducted in the absence of any commercial or financial relationships that could be construed as a potential conflict of interest.

Received: 21 June 2014; accepted: 04 August 2014; published online: 20 August 2014.

Citation: Petre B, Joly DL and Duplessis S (2014) Effector proteins of rust fungi. Front. Plant Sci. 5:416. doi: 10.3389/fpls.2014.00416

This article was submitted to Plant-Microbe Interaction, a section of the journal Frontiers in Plant Science.

Copyright (c) 2014 Petre, Joly and Duplessis. This is an open-access article distributed under the terms of the Creative Commons Attribution License (CC BY). The use, distribution or reproduction in other forums is permitted, provided the original author(s) or licensor are credited and that the original publication in this journal is cited, in accordance with accepted academic practice. No use, distribution or reproduction is permitted which does not comply with these terms. 